\title{
Leer el mundo. Experiencias actuales de transmisión cultural
}

\author{
Michèle Petit (2015). Leer el mundo. Experiencias actuales de transmisión cultural. Fondo de Cultura \\ Económica de Argentina S.A. Buenos Aires. 207 páginas. \\ Elsa Amanda Rodríguez de Moreno*
}

En un mundo en el que la tecnología es cada vez más importante, pues facilita obtener rápidamente la información sobre temas generales y especializados con una amplia representación gráfica y dinámica, llama la atención encontrar este libro cuyo objetivo es valorar la importancia de la lectura.

Los capítulos que incluye son "Te presento el mundo, ¿para qué sirve leer? Variaciones sobre tres vocablos: palabras, comunicar, narración"; "Los libros, el arte y la vida de todos los días"; "Celebración de lo imaginario, el arte de la transmisión”, y, por último, "La educación artística y cultural". Todos ellos de gran importancia para quienes trabajamos en la educación pues reflexiona y enfatiza en la lectura como medio para asumir la cultura de la sociedad, valorándola como medio útil para conocer al otro desde el interior.

Michéle Petit es antropóloga interesada en la sociología, las lenguas orientales y el psicoanálisis. Desde la perspectiva cualitativa, analiza la experiencia de los lectores, la importancia de la lectura para superar conflictos armados, crisis económicas, desplazamientos forzados.

La autora presenta en el primer capítulo el gran significado que tienen las características de un lugar; las cuales nos ayudan a responder una pregunta esencial como es ¿dónde estoy? Generalmente de manera inconsciente, las características físicas de un lugar (la superficie, el cielo, las personas que lo habitan, las formas como esas personas se interrelacionan, los hitos espaciales, la organización de las actividades económicas, culturales, sociales, lúdicas, etc.) nos indican dónde nos encontramos y, dado ese conocimiento que no cuestionamos, nos dan la seguridad para actuar, desplazarnos, interrelacionarnos con los demás y llevar una vida cómoda. Lo espacial no nos inquieta, todo es muy familiar, por lo que nuestras inquietudes se cifran en los objetivos con los que salimos del hogar: trabajar, estudiar, comprar, vender, resolver problemas administrativos, bancarios, etc.

Sin embargo, cuando visitamos por un corto o largo tiempo otro país, nos desorientamos, desconocemos las características del firmamento, del medio rural o urbano en que nos encontramos, difieren las costumbres, las actitudes, pero especialmente nuestra mente se ocupa de manera consciente de aquello que observamos en nuestro entorno y difiere del espacio cotidiano. En esas oportunidades es cuando nos hacemos conscientes de lo importante de conocer el espacio en el que vivimos.

Esos bienes materiales o dones, como los llama Milton Santos, representan el acumulado heredado de muchas generaciones que nos antecedieron y nos dejaron un mundo construido según sus conocimientos, escala de valores, cultura; y en esos espacios que percibimos se desenvolvió y se desenvuelve la historia de las personas que lo habitan.

Para quienes vivimos en la zona ecuatorial, es toda una vivencia desplazarnos a países de otras latitudes, donde el invierno se manifiesta, además del frío en la oscuridad prolongada, las noches son largas para nuestra experiencia. Ese mundo lo experimentamos y lo representamos mentalmente por las vivencias pero también por las historias. 
La autora hace una diferenciación entre los términos palabra, comunicar y narración. La palabra vale por sus modulaciones, su ritmo, su canto así no se comprende su significado llama la atención escucharlas y motiva a aprender otro idioma o simplemente las palabras encantan y conduce a ampliar la imaginación, las palabras, además de designar los objetos en su presencia, nos permite nombrar la ausencia.

Comunicar es el logro de la intersubjetividad que desde el nacimiento nos permite ponernos en contacto con la madre, con el otro lo que nos permite construir significados. Narrar es esencial para organizar la experiencia, para construir una continuidad entre el pasado, el presente y lo posible; "es poner en orden los acontecimientos en el tiempo" (p. 93).

Otro capítulo interesante en cuanto estimula la valoración del arte es el denominado "Los libros, el arte y la vida de todos los días"; en él se narran experiencias en diferentes partes del mundo donde personas de todas la edades y estratos sociales se reúnen para socializar alrededor de la poesía, del cine, de la música, de la lectura facilitando así la apropiación de la cultura escrita. Michèle Petit afirma: "Proponer literatura y obras de arte es animar el espacio concreto, darle sentido" (p. 112), y tiene razón ya que el mundo cotidiano, rutinario, material, mediante la literatura se abre a todo un territorio interior de conocimiento que debemos aprovechar y reconocer.

Definitivamente, el libro aporta reflexiones sobre la función de la lectura como un vehículo, tal vez el más importante, en la interiorización de la cultura en todos los aspectos: sociales, económicos, morales, geográficos, históricos, artísticos..., pero, además, es una forma que nos permite conocernos a nosotros mismos, valorar nuestras capacidades, objetivizar nuestras formas de ser, de sentir, de pensar, de comunicarnos.

Mediante la lectura sanamos nuestra alma, expresamos nuestros miedos, dolores, frustraciones y retornamos, mediante la memoria a espacios geográficos, a escenas familiares, íntimas, que nos motivan a seguir adelante a pesar de nuestras limitaciones, a disfrutar todo aquello que nos rodea, a construir nuevos conocimientos del entorno y de los otros; en síntesis, a vivir mejor. 